\title{
Factors associated with adults' actions to confirm their own rubella immune status in Japan's drive toward rubella elimination: Cross-sectional online survey of non- healthcare workers in their 20s to 40 s
}

\author{
Masataro Norizuki ${ }^{1,2}, \mathrm{Ai} \mathrm{Hori}^{3}$ and Koji Wada ${ }^{1 *}$ (D)
}

\begin{abstract}
Background: Rubella outbreaks occurred among adults in Japan in 2013-2014 and 2018-2019 due to immunity gaps. In response and aiming at rubella elimination by 2020, the government introduced countermeasures comprising supplementary immunization activities for voluntary testing of adult non-healthcare-related workers and vaccination of susceptible individuals. However, as of October 2020, rubella immunity testing and vaccination rates remained low. This study was conducted to identify factors associated with adults voluntarily confirming their rubella immune status, to help develop effective promotion activities for hard-to-reach and left-behind populations.

Methods: In this cross-sectional study, a general population sample of non-healthcare workers aged 20-49 years in Japan completed an online survey in November 2020. Univariate analysis was performed to examine associations of specific actions taken to confirm rubella immune status with social background characteristics, knowledge of rubella, and attitude to testing and vaccination. Log binomial regression analysis was performed to explore the associations following adjustment for social background characteristics.

Results: Among 1,854 respondents (927 men, 927 women), only 23.4\% of men and 39.4\% of women in their 20s to 40s have taken some action related to rubella prevention. Three major factors were associated with the targeted population having taken voluntary action: (1) knowing about testing for confirmation of immunity status (adjusted odds ratio [AOR] 4.29 men, 2.89 women), the rubella outbreak in 2013 among men in their 20s to 40s (AOR 2.79 men, 1.64 women), and congenital rubella syndrome (AOR 1.89 men, 3.10 women); (2) having acquaintances who were vaccinated against or tested for rubella (AOR 2.98 men, 1.95 women); and (3) having a positive attitude toward influenza vaccination (AOR 2.48 men, 1.83 women). Marriage, desire for pregnancy, and having children were weakly associated with taking action.
\end{abstract}

\footnotetext{
* Correspondence: kwada-sgy@umin.ac.jp

${ }^{1}$ Graduate School of Medicine, International University of Health and Welfare Graduate School, 4-1-26 Akasaka, Minato, Tokyo 107-8402, Japan

Full list of author information is available at the end of the article
}

C C The Author(s). 2021 Open Access This article is licensed under a Creative Commons Attribution 4.0 International License, which permits use, sharing, adaptation, distribution and reproduction in any medium or format, as long as you give appropriate credit to the original author(s) and the source, provide a link to the Creative Commons licence, and indicate if changes were made. The images or other third party material in this article are included in the article's Creative Commons licence, unless indicated otherwise in a credit line to the material. If material is not included in the article's Creative Commons licence and your intended use is not permitted by statutory regulation or exceeds the permitted use, you will need to obtain permission directly from the copyright holder. To view a copy of this licence, visit http://creativecommons.org/licenses/by/4.0/. The Creative Commons Public Domain Dedication waiver (http://creativecommons.org/publicdomain/zero/1.0/) applies to the data made available in this article, unless otherwise stated in a credit line to the data. 
Conclusions: Currently, insufficient voluntary action is being taken by high-risk adult populations to close the identified immunity gaps. In this last mile to rubella elimination, our findings and suggested potential interventions via annual health check-ups and occupational health and public health initiatives could prove helpful in developing further countermeasures that actively promote and implement supplementary immunization activities targeting all adult generations.

Keywords: Rubella, Vaccine-preventable disease, Knowledge, Attitude, Immunization policy, Supplementary immunization activities

\section{Background}

Population immunity of at least $83 \%$ is needed to achieve herd immunity and interrupt transmission of endemic rubella virus [1]. Routine immunization with rubella-containing vaccine has dramatically decreased infections, and rubella has been successfully eliminated in some countries and regions [2]. However, even in some countries that have achieved high vaccination coverage in childhood, outbreaks have occurred among adults [3, 4]. In Japan in 2013, a rubella outbreak occurred among the working-age population that had not been previously vaccinated; 14,344 adults mostly in their 20 s to 40 s were infected and 45 cases of congenital rubella syndrome (CRS) were recorded [5-7].

This 2013 outbreak was due to immunity gaps. In 1977, the government had started a rubella vaccination program for adolescent females (age 12-15 years) to prevent CRS and the policy continued until 1995, when universal infant immunization was introduced. Vaccinations programs started in 1989 for the first dose of measlesrubella vaccine and in 2006 for the second dose [8]. The historical routine immunization of adolescent females, subsequent introduction of childhood immunization, and lack of supplementary immunization activities (SIAs) for testing of adults resulted in immunity gaps among adults born before April 1, 1990 who were not infected with rubella naturally and who did not have the opportunity to be vaccinated twice.

As a countermeasure to the 2013 outbreak, from 2014 the government introduced voluntary-based SIAs for adults. To promote vaccination uptake before pregnancy and prevent CRS cases, the government started providing financial support to women of childbearing age and their partners for antibody testing [9]. Despite these efforts, another outbreak occurred in 2018-2019 mainly among rubella-susceptible adult males [10], and 5 CRS cases were reported [11]. As an additional countermeasure and to try to meet Japan's target of rubella elimination by 2020, in 2019 the government also began testing adult males for immunity and vaccinating males born between April 2, 1962 and April 1, 1979, who had no opportunity to receive routine vaccination against rubella and who were found by an antibody test to have a lower seroprevalence of rubella-specific antibody than other age groups $[11,12]$. However, as of October 2020, among the targeted adult male population for example, only $16 \%(2,491,478 / 15,374,162)$ had been tested for rubella immunity $(1,245,330$ in 2019 and 1,246,148 in 2020) [12].

In countries close to eliminating rubella like Japan, vaccination needs to reach all susceptible adults. This requires that individuals confirm their own immune status for rubella, by checking their documented vaccination history or taking a rubella antibody test and getting vaccinated as necessary. However, because testing and vaccination strategies in Japan are voluntary, there is concern that SIA coverage is lower than needed to achieve herd immunity and eliminate rubella. Also, although far fewer rubella cases were reported in 2020 compared with previous years (100 in 2020 [13] vs 2,946 in 2018 [11] and 2,306 in 2019 [11]), social distancing, universal masking, and additional hygiene measures introduced during the novel coronavirus disease 2019 (COVID-19) pandemic likely contributed to this dramatic decrease, and another rubella outbreak may be possible when society opens up again.

We conducted this study in late 2020 to evaluate the latest progress in promoting high-risk adults to voluntarily confirm their rubella immune status. We investigated sociodemographic characteristics and attitudes associated with voluntary action in order to identify ways to help policy makers promote action among high-risk adults with lower immunity, especially those in their 20 s to $40 \mathrm{~s}$ and in hard-to reach or left-behind populations.

\section{Methods}

\section{Participant enrollment}

This cross-sectional study was conducted with a general population sample in Japan. Participants were recruited by an online survey company (Macromill, Inc. Tokyo, Japan). All registered candidates had agreed to participate in online surveys and could withdraw consent at any time, and additionally read the study information before specifically agreeing online to participate in this study, with the option to withdraw up until submitting their answers. Thus, written consent was not obtained. The institutional ethics committee approved this protocol. 
Inclusion criteria were age 20-49 years and agreement to participate. Individuals were excluded if they were registered as healthcare-related workers according to 12 occupation categories and 43 subcategories used by the survey company (e.g., doctors, nurses, pharmacists, administrative staff working in hospitals, and employees of healthcare companies in order to better represent the general population, because healthcare workers tend to be vaccinated).

In November 2020, from a list of 10 million individuals, the survey company randomly selected 6,000 eligible participants $-1,000$ men and 1,000 women in three different age groups (20-29, 30-39, and 40-49 years)and invited them to participate. Registrants were provided financial incentives for their participation. Sample size was calculated based on a margin of error of $6 \%$, assuming $50 \%$ of the target population in each stratum $(3,500,000$ men and 3,500,000 women), with $95 \%$ confidence intervals, to obtain 267 per stratum. We decided on a sample size of 300 for each of the six strata, and recruitment was ended once approximately 1,800 participants agreed to participate (Figure 1). Participants who did not answer all of the questions or answered in too short a time were excluded from the final analysis.

\section{Questionnaire data collection Demographic information}

The survey company provided basic demographic information on age, sex, marital status, and having children or not. Questionnaire items included additional basic demographic information, highest education level (high school or lower/junior college,/university/graduate school/no answer), and desire for pregnancy ("Are you, or your partner, pregnant or plan to get pregnant?" [Yes/No/I don't know]).

\section{Knowledge about rubella}

To evaluate knowledge of rubella, based on current strategy and the government's promotion for rubella elimination, we created three items on knowledge about the testing and vaccination strategy, the 2013 rubella outbreak, and CRS. Participants answered whether they knew or did not know the following information: "A blood test (antibody test) can be done to determine whether someone has been vaccinated against rubella or has previously had rubella" (I knew that/I did not know that); "In 2013, there was a rubella epidemic, mainly among men in their 20s to 40s" (I knew that/I did not know that); and "Women who are infected with rubella during pregnancy may give birth to children with congenital rubella syndrome. (Congenital rubella syndrome: difficulty hearing, heart deformities, sight problems, delayed mental or physical development, other congenital disorders)" (I knew that/I did not know that).

\section{Attitude to testing and vaccination}

We created two questions to reveal attitude toward testing and vaccination. To determine whether participants' acquaintances had been vaccinated against rubella, the first question asked, "Since the 2013 epidemic, have any of your acquaintances (people you can contact by phone or email) had a rubella blood test (antibody test) or been vaccinated for rubella?" (Yes/No/I don't know). To determine acceptance of vaccination, the second question asked, "Do you get an influenza vaccine?" (Every year/Almost every year/ Sometimes/Never/I don't know).

\section{Actions to confirm rubella immune status}

To identify whether respondents had taken action to confirm their rubella immune status, we asked the following three questions about action taken after the 2013 rubella outbreak in Japan: "Since the 2013 rubella epidemic, have you checked your Maternal and Child Health Handbook or other vaccination records to confirm whether you have been vaccinated for rubella?" (Yes/No/I don't know); "Since the 2013 rubella epidemic, have you had a blood test (antibody test)?" (Yes/No/I don't know); and "Since the 2013 rubella epidemic, have you had a rubella vaccination?" (Yes/No/I don't know). We combined the answers to these three questions to generate a binary outcome variable; if respondents answered affirmatively to any of the three questions, we defined them as having taken action to confirm their rubella immune status.

\section{Statistical analysis}

We performed univariate analysis using Pearson's chisquared test to examine the potential relationship between each of the three actions taken to confirm rubella immune status and social background, knowledge, or attitude. Log binomial regression analysis was then performed to explore the associations with adjustment for social background characteristics. All demographic variables were included in the primary model and all were shown to be significant in univariate analysis $(P<0.05)$ in this study or in previous studies [14-21]. The final model was adjusted for all variables. IBM SPSS Statistics 19 software (IBM Corporation, Armonk, NY) was used for all analysis.

\section{Ethical considerations}

The study protocol was reviewed and approved by the Ethics Committee of the International University of Health and Welfare, Tokyo, Japan (approval number 18Im-010). 


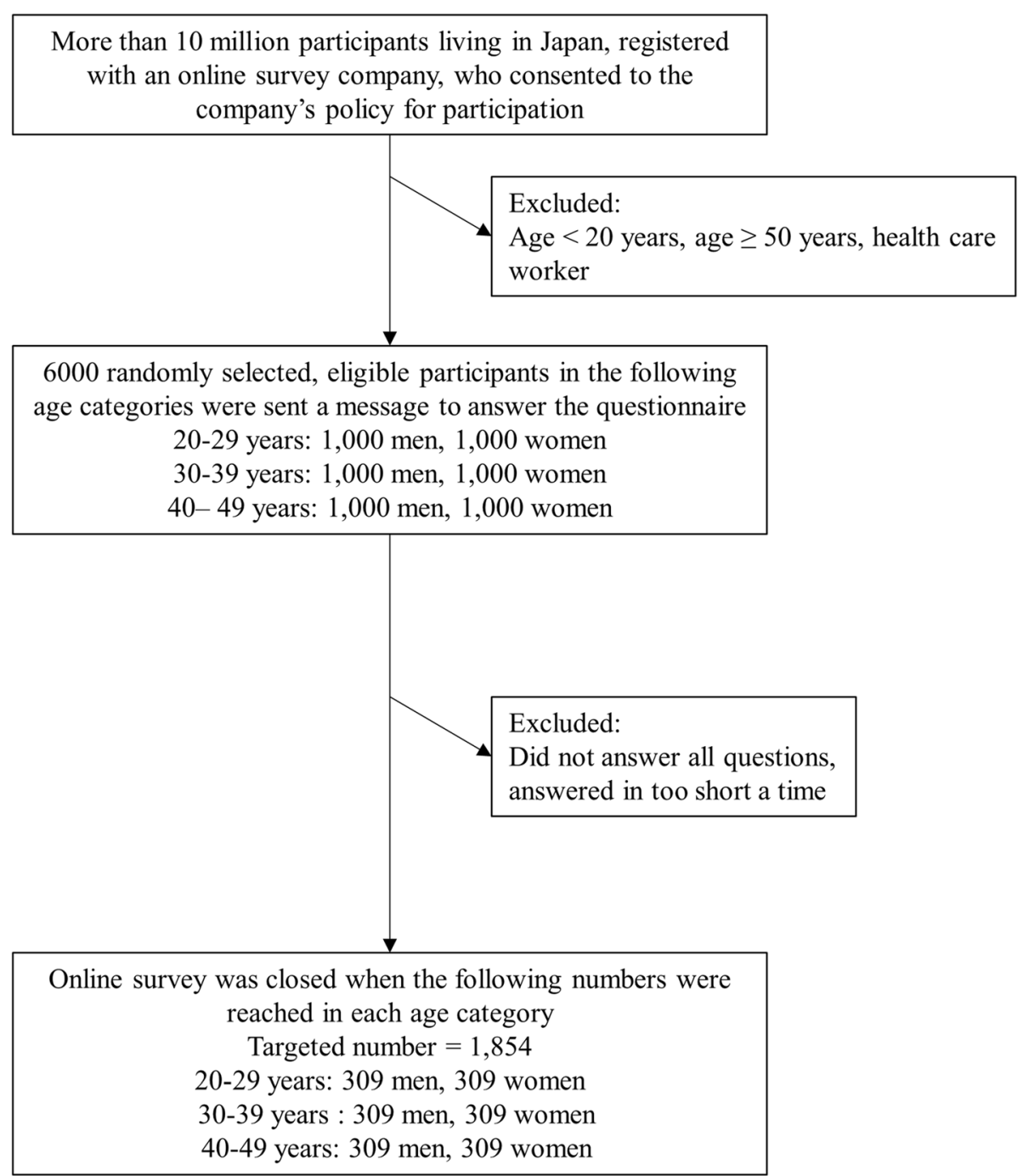

Fig. 1 Participant flow in this cross-sectional online survey of non-healthcare workers in their 20s to 40s. Participants were enrolled from among non-healthcare workers aged 20 to 49 who had registered with an online survey company (Macromill, Inc. Tokyo, Japan). The survey company sent a message to 6,000 randomly selected registrants comprising 1,000 men and 1,000 women in three different age groups (20-29, 30-39, and 40-49 years). Recruitment was ended once approximately 1,800 participants agreed to participate, and ultimately 309 men and women in the three different age groups participated

\section{Results}

\section{Participants}

A total of 1,854 participants, 927 men and 927 women, participated in the web survey, which was conducted in mid-November 2020. Table 1 shows the participants' sociodemographic characteristics and their reported actions to confirm their rubella immune status. More than $70 \%$ of female participants reported knowing about CRS, compared with less than half of male participants. More women than men had taken one or more of the three listed actions to confirm their rubella immune status (39.4\% and $23.4 \%$, respectively). Rubella antibody testing was the most common measure to confirm immune status among men and documented vaccination history was the most common measure to confirm immune status among women, with no significant difference found between the sexes.

\section{Binomial logistic regression analysis}

Table 2 shows the prevalence of action taken to confirm immune status for rubella prevention stratified by sociodemographic background among men and women. Overall, $66.0 \%$ of men and $74.8 \%$ of women who had acquaintances who got vaccinated or tested for rubella took action to confirm own immune status for rubella. Among the different age groups, only $25.2 \%$ of women aged 40-49 years took action to confirm their rubella immune status. 
Table 1 Sociodemographic characteristics of the 1,854 participants in this online survey (November 2020)

\begin{tabular}{|c|c|c|c|c|}
\hline & \multicolumn{2}{|l|}{ Men } & \multicolumn{2}{|l|}{ Women } \\
\hline & $n=927$ & (\%) & $n=927$ & (\%) \\
\hline \multicolumn{5}{|l|}{ Having knowledge about } \\
\hline Confirmation of immune status by testing & 259 & $(27.9)$ & 428 & $(46.2)$ \\
\hline 2013 rubella outbreak in men in their 20s-40s & 279 & $(30.1)$ & 358 & $(38.6)$ \\
\hline Congenital rubella syndrome & 393 & $(42.4)$ & 677 & $(73.0)$ \\
\hline \multicolumn{5}{|c|}{ Having acquaintances who got vaccinated or tested for rubella } \\
\hline Yes & 94 & $(10.1)$ & 147 & $(15.9)$ \\
\hline No/ Don't know & 833 & $(89.9)$ & 780 & $(84.1)$ \\
\hline \multicolumn{5}{|l|}{ Receiving influenza vaccination } \\
\hline Every year & 184 & (19.8) & 185 & $(20.0)$ \\
\hline Almost every year & 134 & $(14.5)$ & 143 & (15.4) \\
\hline Sometimes & 223 & $(24.1)$ & 234 & $(25.2)$ \\
\hline Never & 365 & (39.4) & 350 & $(37.8)$ \\
\hline Don't know & 21 & (2.3) & 15 & (1.6) \\
\hline \multicolumn{5}{|l|}{ Marital status } \\
\hline Married & 342 & $(36.9)$ & 492 & $(53.1)$ \\
\hline Single & 585 & $(63.1)$ & 435 & $(46.9)$ \\
\hline \multicolumn{5}{|l|}{ Desire for pregnancy } \\
\hline Yes & 260 & $(28.0)$ & 306 & $(33.0)$ \\
\hline No/ Don't know & 667 & $(72.0)$ & 621 & $(67.0)$ \\
\hline \multicolumn{5}{|l|}{ Having a child/children } \\
\hline Yes & 281 & $(30.3)$ & 400 & $(43.1)$ \\
\hline No/ Don't know & 646 & $(69.7)$ & 527 & $(56.9)$ \\
\hline \multicolumn{5}{|l|}{ Age, years } \\
\hline $20-29$ & 309 & (33.3) & 309 & $(33.3)$ \\
\hline $30-39$ & 309 & (33.3) & 309 & (33.3) \\
\hline $40-49$ & 309 & (33.3) & 309 & (33.3) \\
\hline \multicolumn{5}{|l|}{ Highest education level } \\
\hline High school or lower & 300 & $(32.4)$ & 292 & (31.5) \\
\hline Junior college & 117 & $(12.6)$ & 258 & $(27.8)$ \\
\hline University & 431 & $(46.5)$ & 342 & $(36.9)$ \\
\hline Graduate school & 59 & $(6.4)$ & 26 & $(2.8)$ \\
\hline No answer & 20 & $(2.2)$ & 9 & $(1.0)$ \\
\hline \multicolumn{5}{|c|}{ Taken voluntary action for rubella prevention after 2013 rubella outbreak } \\
\hline Any & 217 & $(23.4)$ & 365 & $(39.4)$ \\
\hline Vaccination history* & 112 & $(12.1)$ & 257 & $(27.7)$ \\
\hline Underwent antibody testing & 129 & $(13.9)$ & 209 & $(22.5)$ \\
\hline Vaccination for rubella & 106 & $(11.4)$ & 148 & (16.0) \\
\hline
\end{tabular}

*Confirmed more than two times from documented vaccination history, such as the Maternal and Child Health Handbook

Table 3 shows the associations found between sociodemographic factors and action taken to confirm rubella immune status among men and women, as determined by binomial logistic regression.

Men and women, but especially men, who knew that testing can confirm immune status were significantly more likely to have taken action to confirm their rubella immune status (men: adjusted odds ratio [AOR] 4.29, 95\% confidence interval [CI] 6.06-11.93; women AOR 2.89, 95\% CI 2.004.18). Similarly, both men and women who knew about the rubella outbreak in 2013 and about CRS were significantly more likely to have taken action to prevent rubella infection. 
Table 2 Prevalence of action for rubella prevention stratified by sociodemographic background among working-age men and women

\begin{tabular}{|c|c|c|c|c|c|c|c|c|}
\hline & \multicolumn{4}{|l|}{ Men } & \multicolumn{4}{|l|}{ Women } \\
\hline & \multicolumn{2}{|c|}{$\begin{array}{l}\text { Action for rubella } \\
\text { prevention }\end{array}$} & \multicolumn{2}{|c|}{$\begin{array}{l}\text { No action for rubella } \\
\text { prevention }\end{array}$} & \multicolumn{2}{|c|}{$\begin{array}{l}\text { Action for rubella } \\
\text { prevention }\end{array}$} & \multicolumn{2}{|c|}{$\begin{array}{l}\text { No action for rubella } \\
\text { prevention }\end{array}$} \\
\hline & $n=217$ & $(\%)$ & $n=710$ & (\%) & $n=365$ & (\%) & $n=562$ & $(\%)$ \\
\hline \multicolumn{9}{|l|}{ Having knowledge about } \\
\hline Confirmation of immune status by testing & 138 & $(53.1)$ & 121 & $(46.7)$ & 256 & $(59.8)$ & 172 & $(40.2)$ \\
\hline 2013 rubella outbreak in men in their 20s-40s & 131 & $(47.0)$ & 148 & $(53.0)$ & 191 & $(53.4)$ & 167 & $(46.6)$ \\
\hline Congenital rubella syndrome & 160 & $(40.7)$ & 233 & $(59.3)$ & 328 & $(48.4)$ & 349 & $(51.6)$ \\
\hline \multicolumn{9}{|c|}{ Having acquaintances who got vaccinated or tested for rubella } \\
\hline Yes & 62 & $(66.0)$ & 32 & $(34.0)$ & 110 & $(74.8)$ & 37 & $(25.2)$ \\
\hline No/ Don't know & 155 & $(18.6)$ & 678 & $(81.4)$ & 255 & $(32.7)$ & 525 & $(67.3)$ \\
\hline \multicolumn{9}{|l|}{ Receiving influenza vaccination } \\
\hline Every year & 78 & $(42.4)$ & 106 & $(57.6)$ & 102 & $(55.1)$ & 83 & $(44.9)$ \\
\hline Almost every year & 41 & $(30.6)$ & 93 & $(69.4)$ & 72 & $(50.3)$ & 71 & $(49.7)$ \\
\hline Sometimes & 50 & $(22.4)$ & 173 & $(77.6)$ & 97 & $(41.5)$ & 137 & $(58.5)$ \\
\hline Never & 46 & $(12.6)$ & 319 & $(87.4)$ & 92 & $(26.3)$ & 258 & $(73.7)$ \\
\hline Don't know & 2 & $(9.5)$ & 19 & $(90.5)$ & 2 & $(13.3)$ & 13 & $(86.7)$ \\
\hline \multicolumn{9}{|l|}{ Marriage } \\
\hline Married & 121 & $(35.4)$ & 221 & $(64.6)$ & 242 & $(49.2)$ & 250 & $(50.8)$ \\
\hline Single & 96 & $(16.4)$ & 489 & (83.6) & 123 & $(28.3)$ & 312 & $(71.7)$ \\
\hline \multicolumn{9}{|l|}{ Desire for pregnancy } \\
\hline Yes & 81 & $(31.2)$ & 179 & $(68.8)$ & 148 & $(48.4)$ & 158 & $(51.6)$ \\
\hline No/ Don't know & 136 & $(20.4)$ & 531 & (79.6) & 217 & $(34.9)$ & 404 & $(65.1)$ \\
\hline \multicolumn{9}{|l|}{ Having a child/children } \\
\hline Yes & 108 & $(38.4)$ & 173 & $(61.6)$ & 211 & $(52.8)$ & 189 & $(47.3)$ \\
\hline No/Don't know & 109 & $(16.9)$ & 537 & $(83.1)$ & 154 & $(29.2)$ & 373 & $(70.8)$ \\
\hline \multicolumn{9}{|l|}{ Age, years } \\
\hline $20-29$ & 64 & $(20.7)$ & 245 & (79.3) & 124 & $(40.1)$ & 185 & $(59.9)$ \\
\hline $30-39$ & 64 & $(20.7)$ & 245 & (79.3) & 163 & $(52.8)$ & 146 & $(47.2)$ \\
\hline $40-49$ & 89 & $(28.8)$ & 220 & $(71.2)$ & 78 & $(25.2)$ & 231 & $(74.8)$ \\
\hline \multicolumn{9}{|l|}{ Highest education level } \\
\hline High school or lower & 53 & $(17.7)$ & 247 & $(82.3)$ & 88 & $(30.1)$ & 204 & $(69.9)$ \\
\hline Junior college & 26 & $(22.2)$ & 91 & $(77.8)$ & 106 & $(41.1)$ & 152 & $(58.9)$ \\
\hline University & 119 & $(27.6)$ & 312 & $(72.4)$ & 153 & $(44.7)$ & 189 & $(55.3)$ \\
\hline Graduate school & 17 & $(28.8)$ & 42 & $(71.2)$ & 16 & $(61.5)$ & 10 & $(38.5)$ \\
\hline No answer & 2 & $(10.0)$ & 18 & $(90.0)$ & 2 & $(22.2)$ & 7 & (77.8) \\
\hline
\end{tabular}

Men and women who took action to confirm their rubella immune status were more likely to have acquaintances who had received a rubella vaccination or had taken the antibody test (men: AOR 2.98, 95\% CI 1.705.23; women: AOR 2.95, 95\% CI 1.84-4.71). Both men and women who got an influenza vaccination every year were more likely to take action compared with those who never got an influenza vaccination (men: AOR 2.48, 95\% CI 1.47-4.17; women: AOR 1.83, 95\% CI 1.17-2.86).
Women with one or more children were significantly more likely to have taken action to confirm their rubella immune status (AOR 2.05, 95\% CI 1.28-3.30), but only a weak association was seen among men (AOR 1.73, 95\% CI 0.93-3.22).

Both being married and wanting to get pregnant tended to be associated with having taken action to confirm immune status in univariate analysis; however, the significance was weak after multivariate adjustment in 
Table 3 Statistical associations between action for rubella prevention and sociodemographic background

\begin{tabular}{|c|c|c|c|c|c|c|c|c|}
\hline & \multicolumn{4}{|l|}{ Men } & \multicolumn{4}{|c|}{ Women } \\
\hline & $\begin{array}{l}\text { Crude } \\
\text { OR }\end{array}$ & $(95 \% \mathrm{Cl})$ & $\begin{array}{l}\text { Adjusted } \\
\text { OR }\end{array}$ & $(95 \% \mathrm{Cl})$ & $\begin{array}{l}\text { Crude } \\
\text { OR }\end{array}$ & $(95 \% \mathrm{Cl})$ & $\begin{array}{l}\text { Adjusted } \\
\text { OR }\end{array}$ & $(95 \% \mathrm{Cl})$ \\
\hline \multicolumn{9}{|l|}{ Having knowledge about } \\
\hline Confirmation of immune status by testing & 8.50 & $(6.06-11.93)$ & 4.29 & $(2.88-6.38)$ & 5.33 & $(4.00-7.10)$ & 2.89 & $(2.00-4.18)$ \\
\hline 2013 rubella outbreak in men in their 20s-40s & 5.78 & $(4.17-8.02)$ & 2.79 & $(1.88-4.14)$ & 2.60 & $(1.98-3.41)$ & 1.64 & $(1.16-2.34)$ \\
\hline Congenital rubella syndrome & 5.75 & $(4.09-8.08)$ & 1.89 & $(1.24-2.89)$ & 5.41 & $(3.70-7.91)$ & 3.10 & $(1.94-4.95)$ \\
\hline \multicolumn{9}{|c|}{ Having acquaintances who got vaccinated or tested for rubella } \\
\hline Yes & 8.48 & $(5.35-13.44)$ & 2.98 & $(1.70-5.23)$ & 6.12 & $(4.10-9.14)$ & 2.95 & $(1.84-4.71)$ \\
\hline No/ Don't know & Ref & & & & Ref & & & \\
\hline \multicolumn{9}{|l|}{ Receiving influenza vaccination } \\
\hline Every year & 3.20 & $(2.26-4.52)$ & 2.48 & $(1.47-4.17)$ & 2.24 & $(1.62-3.10)$ & 1.83 & $(1.17-2.86)$ \\
\hline Almost every year & 1.55 & $(1.03-2.31)$ & 1.49 & $(0.82-2.70)$ & 1.70 & $(1.19-2.43)$ & 1.53 & $(0.94-2.48)$ \\
\hline Sometimes & 0.93 & $(0.65-1.33)$ & 1.55 & $(0.93-2.60)$ & 1.12 & $(0.83-1.52)$ & 1.58 & $(1.04-2.40)$ \\
\hline Never & Ref & & & & Ref & & & \\
\hline Don't know & 0.38 & $(0.08-1.46)$ & 0.68 & $(0.11-4.36)$ & 0.23 & $(0.05-1.04)$ & 1.60 & $(0.32-8.12)$ \\
\hline \multicolumn{9}{|l|}{ Marriage } \\
\hline Married & 2.79 & $(2.04-3.80)$ & 1.03 & $(0.56-1.91)$ & 2.46 & $(1.87-3.23)$ & 1.39 & $(0.93-2.06)$ \\
\hline Single & Ref & & & & Ref & & & \\
\hline \multicolumn{9}{|l|}{ Desire for pregnancy } \\
\hline Yes & 1.77 & $(1.28-2.44)$ & 1.54 & $(0.98-2.41)$ & 1.74 & $(1.32-2.30)$ & 1.39 & $(0.93-1.71)$ \\
\hline No/Don't know & Ref & & & & Ref & & & \\
\hline \multicolumn{9}{|l|}{ Having a child/children } \\
\hline Yes & 3.08 & $(2.24-4.22)$ & 1.73 & $(0.93-3.22)$ & 2.70 & $(2.06-3.55)$ & 2.05 & $(1.28-3.30)$ \\
\hline No/ Don't know & Ref & & & & Ref & & & \\
\hline \multicolumn{9}{|l|}{ Age, years } \\
\hline $20-29$ & Ref & & & & Ref & & & \\
\hline $30-39$ & 0.79 & $(0.57-1.10)$ & 0.83 & $(0.49-1.39)$ & 2.30 & $(1.74-3.04)$ & 1.11 & $(0.73-1.68)$ \\
\hline $40-49$ & 1.55 & $(1.13-2.12)$ & 1.25 & $(0.72-2.15)$ & 0.39 & $(0.29-0.53)$ & 0.17 & $(0.10-0.29)$ \\
\hline \multicolumn{9}{|l|}{ Highest education level } \\
\hline High school or lower & 0.61 & $(0.43-0.86)$ & 0.85 & $(0.54-1.33)$ & 0.56 & $(0.42-0.75)$ & 0.83 & $(0.56-1.24)$ \\
\hline Junior college & 0.93 & $(0.58-1.47)$ & 1.06 & $(0.58-1.92)$ & 1.10 & $(0.82-1.48)$ & 1.11 & $(0.73-1.68)$ \\
\hline University & Ref & & & & Ref & & & \\
\hline Graduate school & 1.35 & $(0.75-2.43)$ & 0.85 & $(0.40-1.82)$ & 2.53 & $(1.14-5.64)$ & 2.51 & $(0.94-6.68)$ \\
\hline No answer & 0.36 & $(0.08-1.55)$ & 1.10 & $(0.20-6.20)$ & 0.44 & $(0.09-2.12)$ & 0.53 & $(0.80-3.44)$ \\
\hline
\end{tabular}

All listed variables were adjusted for in the final model.

$\mathrm{OR}$, odds ratio; $\mathrm{Cl}$, confidence interval; Ref, reference

men and women. Women aged 40-49 years were less likely to have taken action to confirm their rubella immune status compared with women aged 20-29 years (AOR 0.17, 95\% CI 0.10-0.29), whereas men showed no significant difference between the two age groups (AOR 1.25, 95\% CI 0.72-2.15). Highest education level showed no significant association with taking action.

\section{Discussion}

This study revealed that, as of late 2020, there is currently insufficient voluntary action being taken by highrisk adults in the Japanese general population (excluding healthcare-related workers) to confirm their rubella immune status: only $23.4 \%$ of men and $39.4 \%$ of women in their 20 s to 40 s have taken some action related to rubella prevention. Thus, our findings indicate that there is 
still some way to go in achieving rubella elimination in Japan.

The first of the three major factors we found to be associated with the targeted population having taken voluntary action to check their rubella immune status was having knowledge about testing for confirmation of immunity status, about the rubella outbreak in 2013 among men in their 20s to 40s, and about CRS. It has been reported that knowledge about vaccine-preventable disease is closely associated with uptake of the influenza [15, 16], measles-rubella containing [22, 23], hepatitis A [24], and pertussis [25] vaccines. In the present study, knowledge that testing can confirm immune status showed a strong association with taking voluntary action among both men and women (men: AOR 4.29, 95\%CI 6.0611.93; women AOR 2.89, 95\% CI 2.00-4.18). This suggests that Japan's test and vaccination strategy has successfully prompted some of those reached by the promotion to actually take action. Further evidence that Japan's current strategies are working are our findings that working-age men have become more aware of their role in CRS following the 2013 outbreak. An effective intervention to reach more of the 20- to 40-year-old target population could involve providing further information in the workplace about rubella the need to check immune status, and how to check it, via posters, pamphlets, or possibly occupational health activities inside larger companies.

The second factor that we found to be associated with taking voluntary action was having acquaintances who were vaccinated against or tested for rubella, and this association was found for both men and women. This is in agreement with the results of previous online surveys about rubella in Japan that reported the association for vaccination [14] and testing [17] of an acquaintance. Learning that a close acquaintance has been vaccinated or tested may instill a sense of security and highlight the benefits of taking action, which may be an effective strategy in collectivist societies like Japan [26]. Given that promotion activities through social networking sites such as Twitter and Facebook [27, 28] and through commercial and social marketing have been shown to be effective for vaccine uptake, activities involving familiar people might also be an effective strategy. Moreover, potential interventions could, for example, involve interested employees voluntarily sharing their experiences of vaccination during promotional activities run by occupational health personnel or encouraging people to share their experiences of testing or vaccination with friends through social networking service (SNS).

Lastly, among both men and women, getting vaccinated every year against influenza was associated with taking voluntary action to confirm rubella immunity, compared with never having been vaccinated against influenza. These findings are in agreement with other studies that have reported the association of annual influenza vaccination behavior with vaccine uptake $[15,16$, 18]. People who have influenza vaccinations every year are likely to worry less about the side effects of the vaccine, be keenly interested in medical care, and have easy access to it. Therefore, it is important that promotions are targeted to reach people who are not interested or do not have easy access to medical care. A possible workplace-related intervention could be to include measurement and explanation of rubella antibody titer at the annual medical check-ups offered by companies in compliance with the labor law. This strategy could reach working-age company employees who are not interested in seeking out medical information, enabling them to easily confirm their immune status.

The life course events of marriage, desire for pregnancy, and having children were associated with taking voluntary action to confirm rubella status, albeit weakly in this study. Getting married tended to be associated with such action among men in the univariate analysis (OR 2.79, 95\% CI 2.04-3.80) but not after multivariate adjustment (AOR 1.03, 95\% CI 0.56-1.91), and men tended not to be interested in rubella before getting married but were more interested after getting married (AOR 1.03, 95\% CI 0.56-1.91). An online study of the general adult population in 2014 also reported voluntary action was strongly associated with getting married [14]. We found that desire for pregnancy and having children showed weak associations with taking action, although the previous 2014 study found a strong association with desire to get married [14]. Also, a recent study conducted in 2020 with Japanese men aged 41-47 years found no association between partner's current desire for pregnancy and undergoing rubella antibody testing (AOR 0.98, 95\% CI 0.87-1.11) [17]. Because all pregnant woman are routinely tested for rubella antibody as part of antenatal care in Japan, experience of pregnancy is a confounder in women and is one of the reasons for the higher OR seen for women with children. Overall, our findings indicate that the switch from measures centered on pregnant women and their partners to measures centered on men in 2019 is having a positive impact, which is encouraging, but we need to reach more men to encourage them to take voluntary action to confirm their rubella immune status.

Surprisingly, we found that women in their 40s were significantly less likely to have taken voluntary action to confirm rubella immune status than those in their 20s. Current promotion activities mainly target pregnant women and men in their 40s, and the free testing and vaccination policy does not cover women without desire for pregnancy. Interest in rubella prevention has clearly fallen among women in their 40s. In addition, a recent 
report from the National Institute of Infectious Diseases indicates that seroprevalence is decreased among those aged 55-69 [29]. It is therefore necessary to design a system that allows all generations to confirm their own immunity with no one left behind.

We did not find an association between highest education level and taking action to confirm rubella immune status. There have been studies that have found an association between education level and vaccine intake-in the Bahamas [19], Lebanon [20], and United States [21] - and those that have found no such association-in Canada [30] and Japan [22]. The high literacy rate, easy access to written information, and high education level among all generations in Japan suggests that promotion activities can make good use of written information.

It seems that more men and women in their 20 s to 40s have taken action as of late 2020 compared with 2013 , when around $25 \%$ of women and men with desire for pregnancy but just $7.3 \%$ of women and $2.9 \%$ of men without a current desire for pregnancy had been tested for rubella antibody or vaccinated against rubella [14]. Even though our findings in late 2020 indicate that still only $39.4 \%$ of women and just $23.4 \%$ of men had taken some action to confirm their immunity, these are more encouraging rates, especially among women. Therefore, it seems then that the government's testing and vaccination strategy that started targeting those with desire for pregnancy and their family members in 2019 is working to some extent [31] to close this identified immunity gap. This would also explain the gap in taking action between women and men in our study. It is important to note, however, that a recent survey in Japan reported that only $21.3 \%$ of men had actually been tested for rubella antibody [32]. So, while our study indicates that the government's promotion activities have been reaching the targeted populations, there are still insufficient numbers of people taking the necessary preventive action to eliminate rubella in the very short term (originally 2020). Further strategies involving, for example, the annual medical check-ups, collaborations in occupational health activities, and encouragement to share experiences with friends through SNS are needed to promote action among those at high risk of rubella infection as well as hard-to-reach and left-behind populations.

Our study had some limitations. First, because data were obtained from a randomly selected online survey population, our findings cannot be considered representative of the general Japanese population as a whole. Second, self-report bias and selection bias may have resulted in overestimation of the results, although given that the targeted age group in their 20 s to 40 s tends to be familiar with information technology and to have internet access, we believe this did not adversely affect our primary objective of identifying factors associated with their participation in the SIAs. Third, this was a cross-sectional study, so we cannot infer causal relationships. Lastly, we did not consider the potential influence of the relationship between the rubella outbreaks and variation in efficacy of the live rubella vaccine across years. However, Japan does have strict quality control standards in place for vaccines [33]. Despite these limitations in study design, we believe that our up-to-date survey results are important to policy makers in deciding how to further accelerate measures for the elimination of rubella in Japan.

\section{Conclusion}

Relying on voluntary action to confirm rubella immunity is currently not a sufficient strategy to reach herd immunity needed for rubella elimination. The main drivers for high-risk working-age adults to confirm their rubella immune status in Japan are (1) having knowledge about confirmation of immunity through testing, the $2013 \mathrm{ru}$ bella outbreak, and CRS, (2) having acquaintances who have had a rubella vaccination or test, and (3) having a positive attitude toward influenza vaccination. In this last mile to rubella elimination, the government should actively promote and implement SIAs to close the identified immunity gaps as well as provide additional ways for adults to easily check their rubella immune status and understand why it matters, such as via annual health check-ups and occupational health and public health initiatives, utilizing digital technology to help achieve this.

\section{Abbreviations}

AOR: adjusted odds ratio; Cl: confidence interval; COVID-19: novel coronavirus disease 2019; CRS: congenital rubella syndrome; OR: Odds ratio; Ref: Reference; SIAs: supplementary immunization activities; SNS: social networking service Social networking service

\section{Acknowledgements}

We would like to thank Caryn Jones of ThinkSCIENCE (Tokyo, Japan) for assistance with writing and editing the manuscript

\section{Authors' contributions}

MN was responsible for the design, analysis, interpretation, and drafting of the manuscript. $\mathrm{AH}$ and $\mathrm{KW}$ revised the manuscript. All authors were involved in drafting the article or revising it critically for important intellectual content and have read and approved the final version of the manuscript.

\section{Funding}

This work was supported by a grant from the National Center for Global Health and Medicine (30-6) and Japan Society for the Promotion of Science KAKENHI (20K10467). The sponsors had no role in study design, in the collection, analysis, or interpretation of data, in the writing of the report, or in the decision to submit the article for publication.

\section{Availability of data and materials}

The datasets used and analyzed during the current study are available from the corresponding author on reasonable request. 


\section{Declarations}

\section{Ethics approval and consent to participate}

The study protocol was reviewed and approved by the Ethics Committee of the International University of Health and Welfare, Tokyo, Japan (18-Im-010). The participants consented to the online survey company's policy for participation.

\section{Consent for publication}

Not applicable.

\section{Competing interests}

The authors declare that they have no competing interests.

\section{Author details}

${ }^{1}$ Graduate School of Medicine, International University of Health and Welfare Graduate School, 4-1-26 Akasaka, Minato, Tokyo 107-8402, Japan. 'Bureau of International Health Cooperation, National Center for Global Health and Medicine, 1-21-1 Toyama, Shinjuku, Tokyo 162-8655, Japan. ${ }^{3}$ Department of Global Public Health, University of Tsukuba, 1-1-1 Tennodai, Tsukuba 305-8577, Japan.

\section{Received: 31 May 2021 Accepted: 28 July 2021}

Published online: 11 August 2021

\section{References}

1. Plans-Rubio P. Evaluation of the establishment of herd immunity in the population by means of serological surveys and vaccination coverage. Hum Vaccin Immunother. 2012;8(2):184-8. https://doi.org/10.4161/hv.18444.

2. Castillo-Solorzano C, Marsigli C, Bravo-Alcantara P, Flannery B, Ruiz Matus C, Tambini $\mathrm{G}$, et al. Elimination of rubella and congenital rubella syndrome in the Americas. J Infect Dis. 2011;204(Suppl 2):S571-8. https://doi.org/10.1093/ infdis/jir472.

3. Panagiotopoulos T, Antoniadou I, Valassi-Adam E. Increase in congenital rubella occurrence after immunisation in Greece: Retrospective survey and systematic review. BMJ. 1999;319(7223):1462-7. https://doi.org/10.1136/ bmj.319.7223.1462.

4. Paradowska-Stankiewicz I, Czarkowski MP, Derrough T, Stefanoff P. Ongoing outbreak of rubella among young male adults in Poland: increased risk of congenital rubella infections. Euro Surveill. 2013;18:20485.

5. National Institute of Infectious Diseases. Rubella and congenital rubella syndrome in Japan as of January 2018. IASR. 2018;39:29-31.

6. Centers for Disease Control and Prevention (CDC). Nationwide rubella epidemic--Japan, 2013. MMWR Morb Mortal Wkly Rep. 2013;62:457-62.

7. Sugishita Y, Takahashi T, Hori N, Abo M. Ongoing rubella outbreak among adults in Tokyo, Japan, June 2012 to April 2013. Western Pac Surveill Response J. 2013:4(3):37-41. https://doi.org/10.5365/wpsar.2013.4.2.011.

8. Kuwabara N, Ching MS. A review of factors affecting vaccine preventable disease in Japan. Hawaii J Med Public Health. 2014;73(12):376-81.

9. Ujiie M, Nabae K, Shobayashi T. Rubella outbreak in Japan. Lancet. 2014; 383(9927):1460-1. https://doi.org/10.1016/s0140-6736(14)60712-1.

10. National Institute of Infectious Diseases. Rubella and congenital rubella syndrome in Japan as of May 2019. IASR. 2019;40:127-8.

11. Ministry of Health, Labour and Welfare. Press Release "Improvement of counter measures for rubella". https://www.mhlw.go.jp/content/10906000/ 000590968.pdf. Accessed 26 May 2021.

12. Ministry of Health, Labour and Welfare. Other infectious disease-related measures (rubella protection, and hospitalization medical expenses for tourists to Japan). https://www.mhlw.go.jp/content/10906000/000706317. pdf. Accessed 12 July 2021

13. National Institute of Infectious Diseases. Epidemiological information for rubella as of 2021 Mar 10. https://www.niid.go.jp/niid/images/epi/rubella/2 021/rubella210310.pdf.

14. Hori A, Wada K, Smith DR. A socio-demographic examination of adults responding to governmental vaccination recommendations during the Japanese rubella outbreak of 2013. PLoS One. 2015;10(6):e0129900. https:// doi.org/10.1371/journal.pone.0129900.

15. Loiacono MM, Mahmud SM, Chit A, van Aalst R, Kwong JC, Mitsakakis N, et al. Patient and practice level factors associated with seasonal influenza vaccine uptake among at-risk adults in England, 2011 to 2016: An age- stratified retrospective cohort study. Vaccine X. 2020;4:100054. https://doi. org/10.1016/j.jvacx.2020.100054.

16. Lin Y, Huang L, Nie S, Liu Z, Yu H, Yan W, et al. Knowledge, attitudes and practices (KAP) related to the pandemic (H1N1) 2009 among Chinese general population: A telephone survey. BMC Infect Dis. 2011;11(1):128. https://doi.org/10.1186/1471-2334-11-128.

17. Hori A, Yoshii S, Isaka Y, Wada K. Factors associated with participation in an ongoing national catch-up campaign against rubella: A cross-sectional internet survey among 1680 adult men in Japan. BMC Public Health. 2021; 21(1):292. https://doi.org/10.1186/s12889-021-10340-8.

18. Redelings MD, Piron J, Smith LV, Chan A, Heinzerling J, Sanchez KM, et al. Knowledge, attitudes, and beliefs about seasonal influenza and H1N1 vaccinations in a low-income, public health clinic population. Vaccine. 2012; 30(2):454-8. https://doi.org/10.1016/j.vaccine.2011.10.050.

19. Blackman E, Thurman N, Halliday D, Butler R, Francis D, Joseph M, et al. Multicenter study of human papillomavirus and the human papillomavirus vaccine: knowledge and attitudes among people of African descent. Infect Dis Obstet Gynecol. 2013;2013:428582-8. https://doi.org/10.1155/2013/428582.

20. El Khoury G, Salameh P. Influenza vaccination: A cross-sectional survey of knowledge, attitude and practices among the Lebanese adult population. Int J Environ Res Public Health. 2015;12(12):15486-97. https://doi.org/10.33 90/ijerph121215000.

21. Kobetz E, Kornfeld J, Vanderpool RC, Finney Rutten LJ, Parekh N, O'Bryan G, et al. Knowledge of HPV among United States Hispanic women: Opportunities and challenges for cancer prevention. J Health Commun. 2010;15(Suppl 3):22-9. https://doi.org/10.1080/10810730.2010.522695.

22. Yahata Y, Fielding JE, Kamiya H, Takimoto N, Ishii J, Fukusumi M, et al. Factors associated with knowledges and attitudes about measles and rubella immunization in a non-health care occupational setting in Japan. J Infect Chemother. 2021;27(5):684-9. https://doi.org/10.1016/j.jiac.2020.12.003.

23. Abd Elaziz KM, Sabbour SM, Dewedar SA. A measles and rubella (MR) catchup vaccination campaign in an Egyptian university: Vaccine uptake and knowledge and attitudes of students. Vaccine. 2010;28(47):7563-8. https:// doi.org/10.1016/j.vaccine.2010.08.053.

24. Bardenheier B, Gonzalez IM, Washington ML, Bell BP, Averhoff F, Massoudi MS, et al. Parental knowledge, attitudes, and practices associated with not receiving hepatitis $\mathrm{A}$ vaccine in a demonstration project in Butte County. California. Pediatrics. 2003;112(4):e269. https://doi.org/10.1542/peds.112.4.e269.

25. Agricola E, Gesualdo F, Alimenti L, Pandolfi E, Carloni E, D'Ambrosio A, et al. Knowledge attitude and practice toward pertussis vaccination during pregnancy among pregnant and postpartum Italian women. Hum Vaccin Immunother. 2016;12(8):1982-8. https://doi.org/10.1080/21645515.2016.1188242.

26. Kawabata M. Is collectivism good for health promotion? Experiences of day labourers in Japan. Glob Health Promot. 2013;20(4):44-51. https://doi.org/1 $0.1177 / 1757975913503384$.

27. Ford AJ, Alwan NA. Use of social networking sites and women's decision to receive vaccinations during pregnancy: A cross-sectional study in the UK. Vaccine. 2018;36(35):5294-303. https://doi.org/10.1016/j.vaccine.2018.07.022.

28. Ahmed N, Quinn SC, Hancock GR, Freimuth VS, Jamison A. Social media use and influenza vaccine uptake among White and African American adults. Vaccine. 2018;36(49):7556-61. https://doi.org/10.1016/j.vaccine.2018.10.049.

29. National Institute of Infectious Diseases. Epidemiological information about rubella for November 18, 2020. https:/www.niid.go.jp/niid/images/epi/ rubella/2020/rubella201118.pdf. Accessed 26 May 2021.

30. Schneeberg A, Bettinger JA, McNeil S, Ward BJ, Dionne M, Cooper C, et al. Knowledge, attitudes, beliefs and behaviours of older adults about pneumococcal immunization, a Public Health Agency of Canada/Canadian Institutes of Health Research Influenza Research Network (PCIRN) investigation. BMC Public Health. 2014;14(1):442. https://doi.org/10.1186/1471-2458-14-442.

31. Jindai K, Funaki T, Nishijima T, Takakura S, Noda H, Miyake K. Towards rubella elimination in Japan. Lancet Infect Dis. 2018;18(7):713-4. https://doi. org/10.1016/s1473-3099(18)30356-6.

32. Ministry of Health, Labour and Welfare. About rubella. https://www.mhlw. go.jp/content/10906000/000645181.pdf. Accessed 26 May 2021.

33. Yongue J. A distinctive nation: vaccine policy and production in Japan. In: Holmberg, C., Blume S., Greenough P, editors. The politics of vaccination: a global history. Manchester University Press, 2017: doi. 10.7765/9781526110916.

\section{Publisher's Note}

Springer Nature remains neutral with regard to jurisdictional claims in published maps and institutional affiliations. 